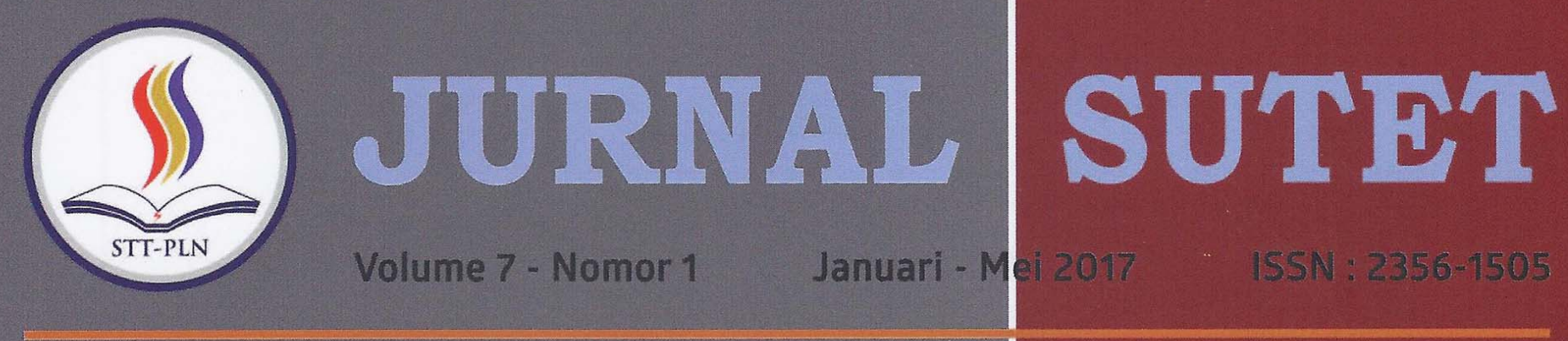

DESAIN SISTEM ALARM MOBIL BERBASIS SMS

Erlina; Hendrianto Husada; Bambang Tri Atmodjo

KELAYAKAN PENGGUNAAN PENDINGIN THERMOELEKTRIK UNTUK PENGHEMATAN DAYA LISTRIK PADA BASE TRANSCEIVER

Sunaryo; Uno Bintang Sudibyo; Supriadi Legino

WITRICITY (WIRELESS ELECTRICITY)

Aas Wasri Hasanah; Oktaria Handayani

CONCEPTUAL DESIGN FOR MITIGATING HARMONIC DISTORTION ON ESP INSTALLATION: CASE STUDY IN KAJI SEMOGA FIELD, MEDCO E\&P INDONESIA

Sandy Suryakusuma; Suprapto Atmowiranto; Dadang Darmawan

RANCANGAN RANGKAIAN ANTI BOUNCING UNTUK RANGKAIAN DIGITAL

Tasdik Darmana

STUDI POWER WHEELING DIKAWASAN INDUSTRI JABABEKA

Bimo Brillianta; Uno Bintang Sudibyo; Wildan Aripin

PEMASANGAN ARRESTER DAN ARCING HORN PADA PENGHANTAR BERISOLASI DI SUTM $20 \mathrm{kV}$ Christine Widyastuti; Andi Makkulau

PENGELOLAAN EMISI GAS LANDFILL (BIOGAS) SEBAGAI ENERGI TERBARUKAN Isworo Pujotomo; Muchamad Nur Qosim

DISAIN SISTEM PENTANAHAN PROTEKSI PETIR SISTEM MULTIPLE VERTICAL ELECTRODES PADA TERMINAL LAWE-LAWE - PERTAMINA DHP

Ibnu Hajar

ANALISA DCS (DISTRIBUTED CONTROL SYSTEM) PADA PROSES POLIMERISASI

Syarif Hidayat; Irsyadi Akbar Jay

PENGEMBANGAN TEKNOLOGI SISTEM SMART MICROGRID DI SEKOLAH TINGGI TEKNIK PLN Heri Suyanto; Agung Hariyanto

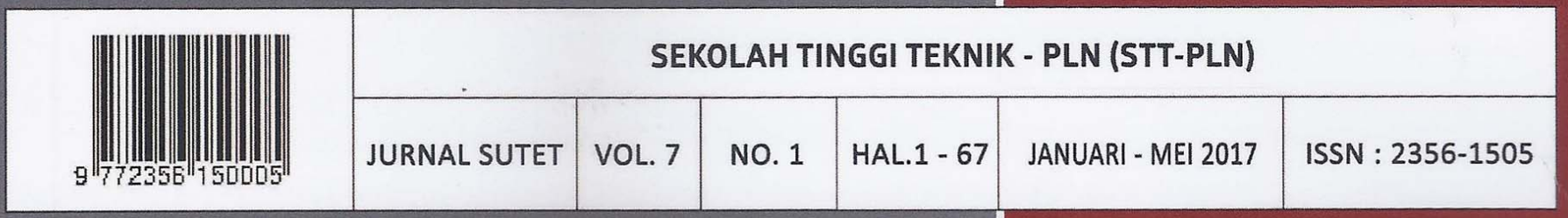




\title{
KELAYAKAN PENGGUNAAN PENDINGIN THERMOELEKTRIK UNTUK PENGHEMATAN DAYA LISTRIK PADA BASE TRANSCEIVER
}

\author{
Sunaryo ${ }^{1)}$, Uno Bintang Sudibyo ${ }^{2)}$,Supriadi Legino ${ }^{3)}$ \\ Teknik Elektro, Sekolah Tinggi Teknik - PLN \\ 1sunaryob1@yahoo.com \\ 2uno@eng.ui.ac.id \\ 33upriadi@sttpln.ac.id
}

\begin{abstract}
Thermoelectrically technology is a technology of solid material that can be used as an alternative cooling technology besides cooling system that uses vapor compression that still uses freon. This study aims to determine the feasibility of using thermoelectrically cooling implementation in the indoor BTS (Base Transceiver Station). The use of this thermoelectrically Cooling is to maintain the ideal temperature of the battery by 25 degrees Celsius $\left(25^{\circ} \mathrm{C}\right)$ which is an ideal temperature. Research is done by testing thermoelectrically by mounting the cooling thermoelectrically in the existing battery cabinets installed in active condition. Ambient temperature measurement is done by using a measuring instrument that has been calibrated.
\end{abstract}

Keywords: Thermoelectric, Base Transceiver Station, BTS, Cooling

Abstrak : Teknologi Thermoelektrik merupakan teknologi material padat yang bisa dijadikan alternatif teknologi pendingin selain sistem pendingin yang menggunakan kompresi uap yang masih memanfaatkan freon. Penelitian ini bertujuan untuk mengetahui kelayakan penggunaan pendingin thermoelektrik di dalam Stasiun Pemancar tipe indoor. Penggunaan dari Pendingin Thermoelektrik ini adalah untuk menjaga suhu ideal ruang baterai sebesar 25 derajat Celcius $\left(25^{\circ} \mathrm{C}\right)$ yang merupakan suhu ideal baterai. Penelitian dilakukan dengan cara melakukan pengujian thermoelektrik dengan menempatkan pendingin thermoelektrik pada lemari baterai eksisting yang dipasang dalam kondisi aktif. Pengukuran temperatur dan lingkungan dilakukan dengan menggunakan alat ukur yang sudah di kalibrasi.

Kata kunci: Thermoelektrik, Stasiun Pemancar, BTS, Pendingin, udara.

\section{PENDAHULUAN}

Pada Base Transceiver Station (BTS) masalah pendinginan baterai dan perangkat telekomunikasi sangat penting. Ada dua jenis BTS yaitu BTS Indoor dan BTS outdoor. Pada penelitian ini yang dibahas adalah BTS Indoor karena pada operator yang diambil datanya, BTS Indoor lebih banyak di bandingkan dengan BTS outdoor.

Pada BTS Indoor konsumsi energy listrik digunakan untuk mencatu kebutuhan daya perangkat telekomunikasi dan pendingin. Kebutuhan daya listrik pendingin mencapai 30\%-50\%. [1].

Sebagian besar dari peralatan BTS menggunakan sumber tegangan $48 \mathrm{~V}$ arus searah, seperti untuk penyearah, kipas, alat pendingin, dan lampu OBL (Obstruction Lamp). Tegangan arus bolak - balik 220 Volt digunakan untuk mencatu pendingin ruangan (Air Conditioner).

Suhu udara luar dan radiasi matahari dapat mempengaruhi suhu di ruang BTS. Pendingin udara dalam BTS dirancang untuk mempertahankan suhu ruang berkisar $25^{\circ} \mathrm{C}-30^{\circ} \mathrm{C}$ [2]. Tujuan dari pendinginan ini adalah untuk mengatasi panas berlebih dari peralatan yang ada di BTS agar bekerja selama 24 jam secara optimal.

Penelitian tentang pengurangan konsumsi energi listrik pada BTS telah dilakukan. Pada tahun 2006 P. Romagnoni et.al, meneliti tentang penggunaan kipas 
(fan) arus searah pada BTS. Pada tahun 2008 Steve N. Roy,et.al. meneliti tentang pengurangan konsumsi energi listrik pada BTS dengan menghilangkan inverter pasif. Pada tahun 2011 Willem Vereecken,et.al, melakukan penelitian tentang pengurangan konsumsi energi listrik pada BTS dengan pemilihan tipe jaringan, sehingga daya listrik untuk pemancar lebih kecil.[3]

Pada tahun 2013 Panagiotis D. Diamantoulakis, et al. meneliti tentang pengurangan konsumsi energi listrik pada BTS dengan mengembangkan sistem smart grid dan pembangkit hybrid yang menggunakan energi terbarukan.[4]

Penelitian ini bertujuan untuk melakukan studi tentang penggunaan pendingin Thermoelectric pada BTS Tipe Indoor untuk penghematan energi listrik.

Manfaat penelitian ini untuk mendapatkan data lapangan yang akurat pada energi listrik pada BTS Indoor dengan penggunaan pendingin Thermoelectric.

\section{LANDASAN TEORI}

Pendingin Thermoelectric merupakan solid state technology yang bisa menjadi alternatif teknologi pendingin selain sistem vapor compression yang masih memanfaatkan refrigerant. Dibandingkan dengan teknologi kompresi uap yang menggunakan refrigerant sebagai media penyerap kalor, teknologi pendingin Thermoelectric relatif lebih ramah lingkungan, tahan lama, dan bisa digunakan dalam skala besar maupun kecil.

Secara umum prinsip kerja dari Thermoelectric adalah berdasarkan efek Seebeck. Apabila ada dua buah logam yang berbeda dihubungkan pada salah satu ujungnya, kemudian diberikan suhu yang berbeda pada sambungan, maka akan terjadi perbedaan tegangan pada ujung yang satu dengan ujung yang lain. Apabila Thermoelectric diberi tegangan, maka Thermoelectric mempunyai dua kemampuan pada dua sisi, sisi pertama menghasilkan dingin dan sisi yang kedua menghasilkan panas.

Perubahan sisi panas dan sisi dingin pada Thermoelectric dipengaruhi oleh polaritas catu tegangan arus searah yang diberikan. Jika sebuah Thermoelectric akan dijadikan sebagai pendingin, maka pada sisi dingin Thermoelectric diberi heatsink dan fan, sehingga pendinginan ini dapat didistribusikan kedalam ruang. Bila polaritas tegangan di balik maka keadaan panas akan berubah menjadi dingin dan begitu juga sebaliknya.

Pendingin Thermoelectric (Thermoelectric cooler) berdasarkan pada efek Peltier. Jika arus listrik melewati rangkaian dari dua konduktor yang tidak sama disitu akan terjadi kenaikan atau penurunan temperatur dipersambungan tergantung dari arah aliran arus listrik. Efek Peltier ini ditemukan oleh Jean Charles Athanase Peltier pada tahun 1834 dan kemudian di perluas oleh Emil Lenz pada tahun 1838. Lenz menunjukkan bahwa air dapat membeku ketika di letakkan pada persambungan bismuth - antimony dengan melewatkan arus listrik melalui persambungan tersebut.

Lenz juga mengamati bahwa jika arus listrik di balik, es dapat meleleh. Dia menyimpulkan bahwa arah dari aliran arus listrik menentukan apakah panas diserap atau dihasilkan pada persambungan.

Ketika masukan listrik diterapkan pada termokopel, elektron bergerak dari bahan tipe-p (semikonduktor yang mempunyai tingkat energy elektron rendah) menuju ke bahan semikonduktor tipe-n (semi konduktor yang mempunyai tingkat energy elektron tinggi) menyerap energi panas yang mengakibatkan sisi tersebut pada sambungan menjadi dingin. elektron - elektron membuang kelebihan energi atau pelepasan kalor pada sambungan panas karena elektron mengalir dari tipe-n kembali ke semikonduktor tipe-p melalui konektor listrik. Membuang panas dari sisi panas tipe-n ke lingkungan yang akan menurunkan temperatur pada sisi dingin tipe-p dengan cepat, besarnya penurunan bergantung dari arus listrik yang diberikan.

Teknologi ini berkembang dengan pesat baik pada bidang aplikasi pendinginan maupun pemanasan setelah adanya perkembangan material semikonduktor. Struktur dari pendingin Thermoelectric dapat dilihat pada Gambar 2.1 . 


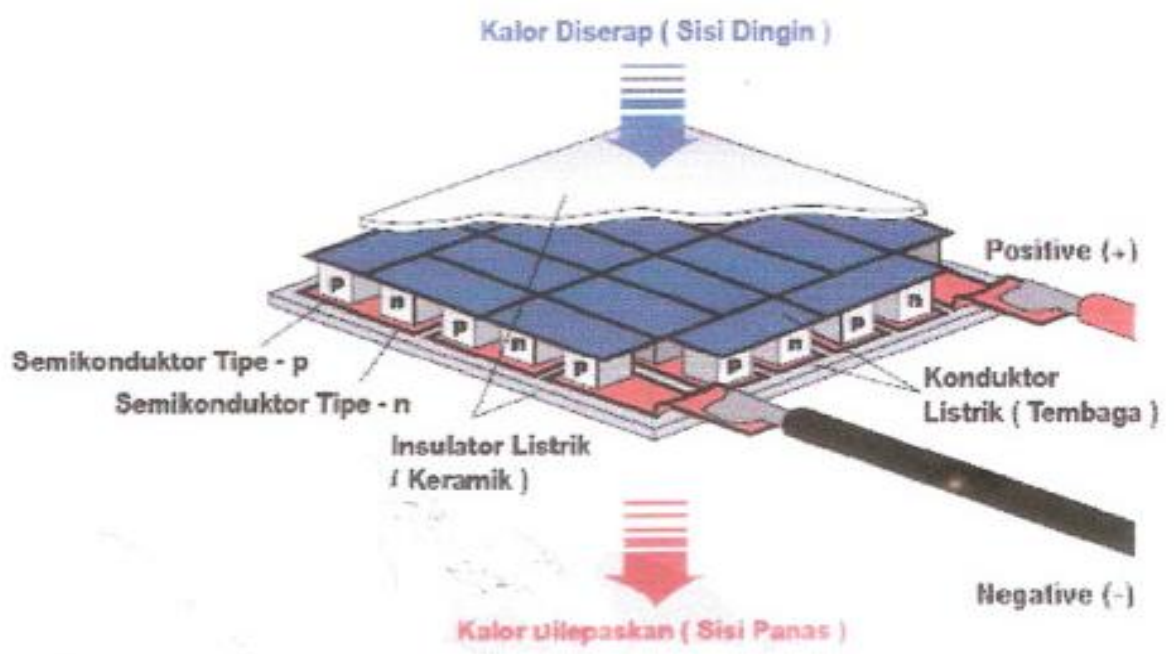

Gambar 2.1. Struktur Pendingin Thermoelectric [5]

Seperti terlihat pada Gambar 2.1 penyerapan kalor dari lingkungan terjadi pada sisi dingin yang kemudian akan dibuang pada sisi panas dari modul Peltier. Sehingga nilai kalor yang dilepaskan pada sisi panas sama dengan nilai kalor yang diserap ditambah dengan daya yang diberikan ke modul.

Dimana :

$$
Q_{h}=Q_{c}+P_{\text {in }}
$$

$\mathrm{Q}_{\mathrm{h}}$ : Kalor yang dilepaskan pada bagian hot side elemen Peltier (Watt)

$Q_{c}$ : Kalor yang diserap pada bagian cold side elemen Peltier (Watt)

$\mathrm{P}_{\text {in }}$ : Daya masukan (Watt)

Pada Gambar 2.1. elektron mengalir dari semikonduktor pada tipe-p yang kekurangan energi, menyerap kalor pada bagian yang didinginkan kemudian mengalir ke semikonduktor tipe-n. semikonduktor tipe-n yang kelebihan energi membuang energi tersebut ke lingkungan dan mengalir ke semikonduktor tipe-p dan seterusnya. Aliran elektron pada suatu Thermoelectric dapat dilihat pada Gambar 2.2.

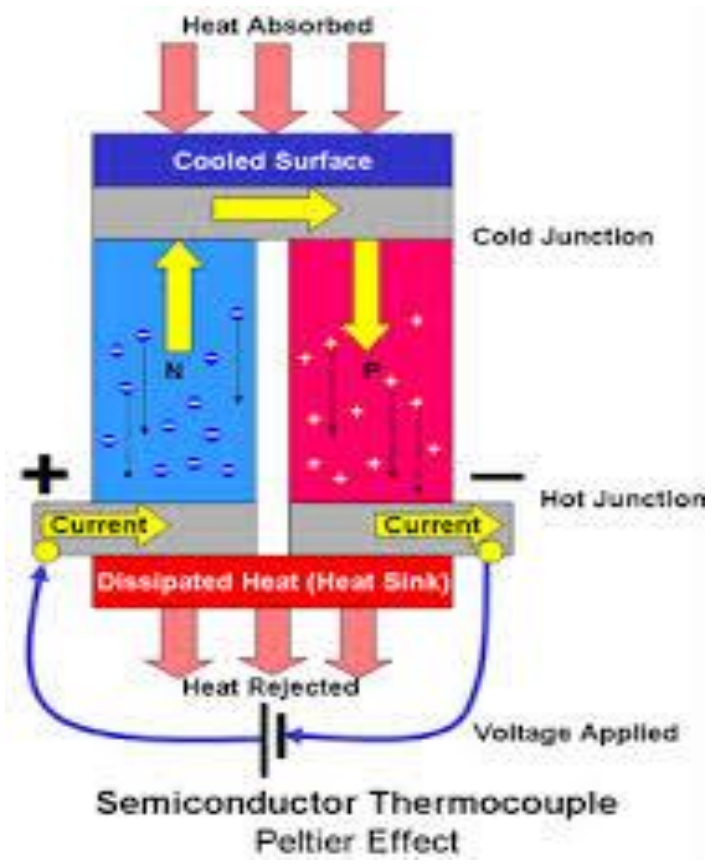

Gambar 2.2. Arah aliran elektron pada modul Thermoelectric

Kelebihan pendingin Thermoelectric antara lain : ketahanan alat yang baik, tidak menimbulkan suara, tidak adanya bagian mekanikal yang bergerak sehingga tidak menimbulkan getaran, perawatan mudah, ukuran yang kecil, ringan, ramah terhadap lingkungan karena tidak menggunakan refrigerant, Thermoelectric dapat juga di gunakan pada lingkungan yang sensitif.

Sedangkan kelemahan Thermoelectric antara lain : efisiensi yang rendah, 
dan adanya kondensasi pada suhu tertentu. Sehingga sampai saat ini pendingin Thermoelectric hanya efektif pada aplikasi untuk objek pendinginan dan daya yang kecil.

\section{METODE PENELITIAN}

Hasil yang diharapkan dari program penelitian ini adalah adanya sinergi yang saling menguntungkan dan saling menunjang antara perguruan tinggi (STT PLN) dan mitra industri untuk menekan penggunaan daya listrik pada Base Transceiver Station Indoor. Konsep pendingin ruang baterai menggunakan komponen thermoelektrik yaitu dengan memanfaatkan sisi dingin pada thermoelektrik. Thermoelectrik berfungsi untuk mendinginkan ruang baterai dengan dilengkapi thermalswitch atau thermostat untuk memutuskan sumber arus (cut off) bila suhu melebihi $70^{\circ} \mathrm{C}$ untuk memproteksi perangkat apabila terjadi panas berlebih. Thermoelektrik bekerja tegangan antara 40 volt sampai dengan 60 volt berjumlah 8 buah dengan pemasangan secara serial untuk menekan konsumsi daya yang dibutuhkan. Sarana Kontrol suhunya dengan mengatur suhu ruangan baterai sesuai dengan suhu ideal yaitu antara $20^{\circ} \mathrm{C}$ sampai dengan $30^{\circ} \mathrm{C}$, dan juga memiliki sarana dry contact otomatis dapat terbuka atau tertutup (NO/NC) yang terkoneksi ke alarm system, yang dapat mengatur sesuai suhu high temp alarm yang diinginkan yaitu kisaran $30^{\circ} \mathrm{C}$ sampai dengan $40^{\circ} \mathrm{C}$, dan dapat dikoneksikan ke Network Operations Centre (NOC) untuk memonitor, baik karena perangkat yang tidak bekerja secara optimal maupun karena perangkat yang rusak agar proteksi terhadap baterai tetap berjalan sebagaimana mestinya.
Metodologi dan tahapan riset yang akan digunakan sebagai berikut :

a. Melakukan Kalibrasi alat ukur suhu dan alat ukur beban.

b. Melakukan analisa pemilihan tempat sensor untuk mengukur suhu sesuai dengan kebutuhan.

c. Melakukan Pembuatan dan Pengujian alat kendali

d. Melakukan pengukuran kinerja thermoelectric sebagai pendingin dengan menggunakan teknik simulasi dan menempatkan 10 buah thermocouple untuk mengukur titik lokasi yang akan dilakukan pengukuran.

e. Melakukan analisa penggunaan daya pada Base Transceiver Station Indoor dan melakukan pemilihan site yang sesuai.

f. Melakukan pengukuran karakteristik beban di lokasi rencana penempatan Pendingin Thermoelectric pada Base Transceiver Station Indoor yang sudah dipilih.

g. Melakukan Analisis Kelayakan Teknis dari penggunaan Pendingin Thermoelectric berdasarkan kajian literature

\section{HASIL DAN PEMBAHASAN}

Sesuai dengan tujuan penelitian ini, maka dilakukan pengujian di Site Sunter Kemayoran Site ID 91553 pada Operator $\mathrm{H} 3 \mathrm{I}$, dengan metode pengambilan data series suhu menggunakan alat temperature data logger yang sudah dikalibrasi. Pengambilan data dimulai dari tanggal 24 Juni 2016 sampai dengan tanggal 28 Juli 2016. Dari hasil pengujian tersebut pada ruang rak baterai didapatkan hasil dengan suhu rata-rata dibawah $25^{\circ} \mathrm{C}$. Hasil dari pegujian ini dapat dilihat pada Gambar 4.1 dibawah ini. 


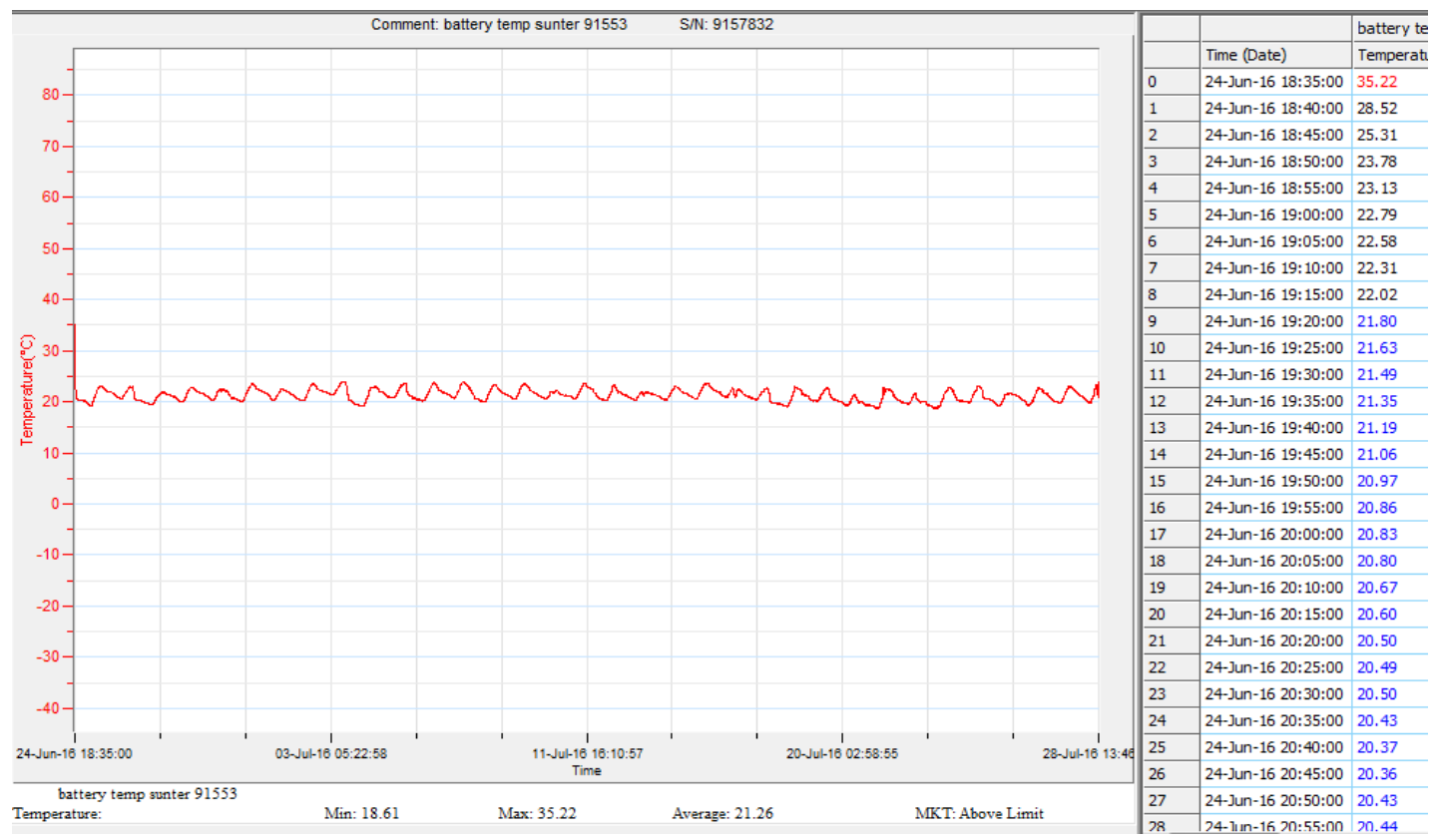

Gambar 4.1. Grafik Hasil Uji Lapangan Thermoelectric Sebagai Pendingin ruang baterai pada BTS Indoor

Pada Gambar 4.1 diatas menunjukkan pada rentang waktu selama periode tanggal 24 Juni 2016 sampai dengan tanggal 28 Juli 2016, suhu minimum sebesar $18,61^{\circ} \mathrm{C}$, Suhu Maksimum sebesar $35,22^{\circ} \mathrm{C}$ dan suhu rata-rata sebesar $21,26^{\circ} \mathrm{C}$.

Untuk Suhu Ruang shelter dijelaskan dengan Gambar 4.2.
Gambar 4.2. menunjukkan hasil pengukuran suhu pada ruang shelter dengan ukuran $3 \mathrm{~m} \times 4 \mathrm{~m} \times 3 \mathrm{~m}$.

Dari Pengujian yang dilakukan mulai dari tanggal 24 Juni 2016 sampai dengan tanggal 28 Juli 2016 didapatkan hasil suhu rata-rata di bawah $40^{\circ} \mathrm{C}$, hasil dari pengujian ini dapat dilihat pada gambar 4.2. di bawah ini.

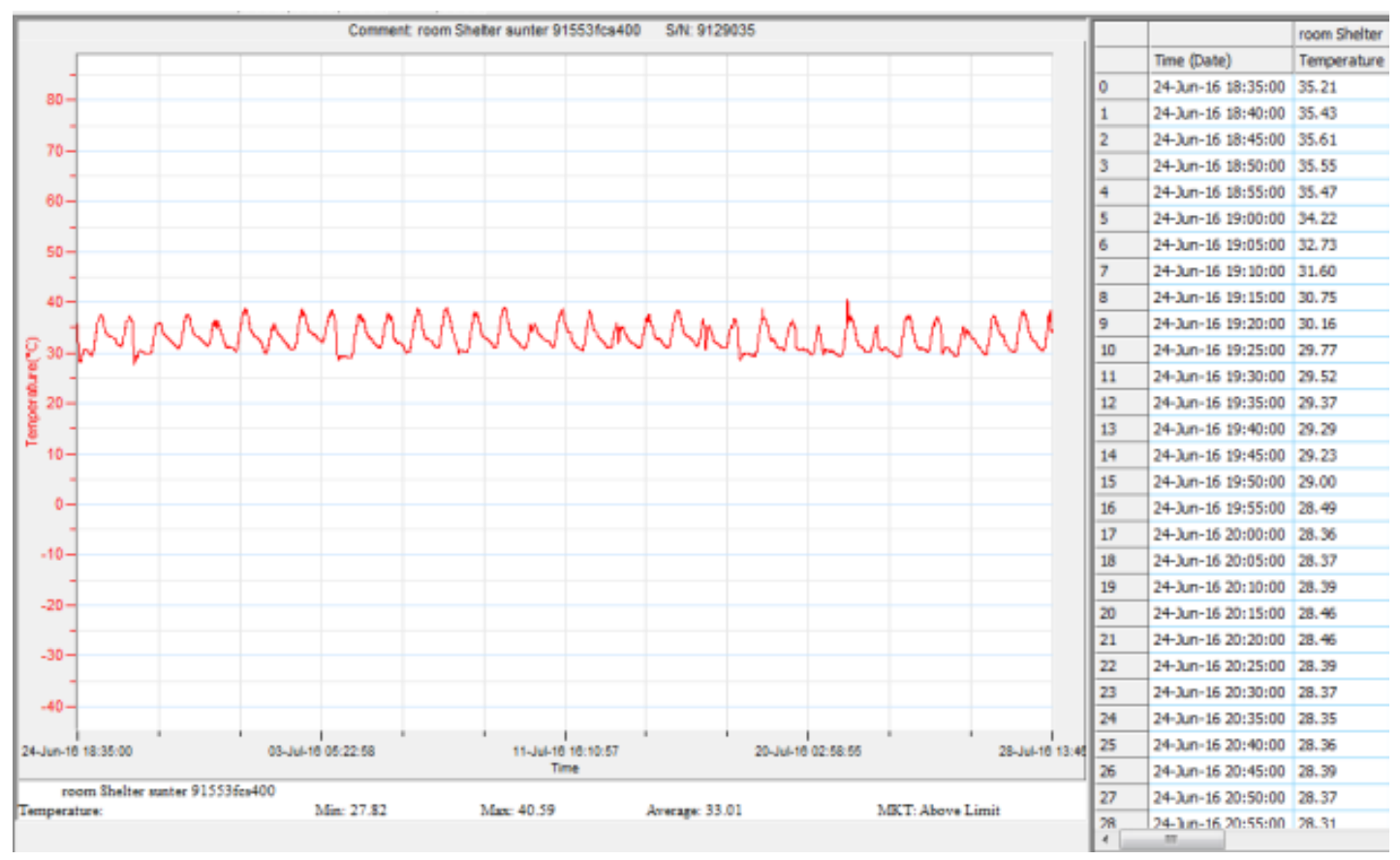

Gambar 4.2.Grafik suhu ruang shelter menggunakan pendingin fan centrifugal 
Pada gambar 4.2. Diatas menunjukkan pada rentang waktu selama periode tanggal 24 Juni 2016 sampai dengan tanggal 28 Juli 2016 suhu minimum adalah sebesar $27,82^{\circ} \mathrm{C}$, Suhu Maksimum sebesar $40,59^{\circ} \mathrm{C}$ dan suhu rata-rata sebesar $33,01^{\circ} \mathrm{C}$.

\section{KESIMPULAN}

1. Penggunaan pendingin Thermoelectric dapat menekan kebutuhan energi listrik pada BTS, sehingga dapat menghemat sebesar $18 \%$ per bulan dari jumlah pemakaian.

2. Daya yang terpakai dalam setiap bulan menunjukan bahwa penggunaan pendingin Thermoelectric mampu mengurangi konsumsi energi listrk sebesar minimal sebesar 344,88 Kwh.

3. Selisih penurunan suhu $(\Delta \mathrm{t})$ pada rak baterai antara suhu kamar dengan suhu dalam rak bateraii sebesar $12^{\circ} \mathrm{C}$, sehingga memenuhi standar kerja baterai yang ideal sebesar $25^{\circ} \mathrm{C}$.

4. Penggunaan pendingin Thermoelectric layak sebagai pilihan utama pendingin pada BTS indoor sebagai pengganti pendingin existing yang menggunakan teknologi Air Compressor.

\section{REFERENSI}

[1] Tada, S.; Echigo, R.; Yoshida. 1997. “ H.A new concept of porous Thermoelectric module using a reciprocating flow for cooling/heating sistem (numerical analysis for heating sistem) Thermoelectrics, Proceedings ICT '97. XVI International Conference on IEEE, Pages: 664 - 667, DOI: 10.1109/ICT.1997.667617.

[2] Seo Young Kim; Keunhee Lee; Sunghoon Park; Jaehoon Kim, .2014.Thermal design analysis and performance test of a $1 \mathrm{~kW}$ Thermoelectric battery cooler Thermal and Thermomechanical Phenomena in elektronic sistems". (ITherm) IEEE Intersociety Conference on Year: 2014 Pages: 1417 - 1421, DOI: 10.1109/ITHERM.2014.6892446,
[3] Lakhkar, N.; Hossain, M.; Agonafer, D. 2008. " CFD modeling of a Thermoelectric device for elektronics cooling applications Thermal and Thermomechanical Phenomena in elektronic sistems, ITHERM 2008. 11th Intersociety Conference on Year: 2008 Pages: 889 - 895.

[4] Manno, M.; Peng Wang; Bar-Cohen, A.2014,." Pulsed Thermoelectric cooling for Improved Suppression of a Germanium Hotspot Components, Packaging and Manufacturing Technology, IEEE Transactions on Year: Volume: 4, Issue: 4 Pages: 602 -611 .

[5] Sarng Woo Karng; Jae-Hoon Shin; Hun Sik Han; Yun Ho Kim; Seo Young Kim.2010. "Thermal performance of a Thermoelectric air-coolingsistem with heat sinks Thermal and Thermomechanical Phenomena in elektronic sistems (ITherm), 12th IEEE Intersociety Conference on Year: Pages: $1-7$.

[6] P. Romagnoni "Low energi Air Conditioning of shelters for Telecommunication Networks" IEEE

[7] Patrick Baier, Frank D"urr, Kurt Rothermel. 2013. Efficient Distribution of Sensing Queries in Public Sensing sistems, IEEE 10th International Conference on Mobile Ad-Hoc and Sensor sistems

[8] Willem Vereecken et.al. 2011. Power Consumption in Telecommunication Networks: Overview and Reduction Strategies IEEE Communications Magazine - June.

[9] Panagiotis D. Diamantoulakis. 2013. Smart hybrid Power sistem for Base Transceiver Stations with Real-Time energi Management IEEE Explore.

[10] www.melcor.com 